\title{
Locally advanced penile carcinoma: classic emasculation or testis-sparing surgery?
}

Lúcio Flávio Gonzaga-Silva, George R. M. Lima, José M. Tavares, Vladmir 0. Pinheiro, George A. Magalhães, Manoel E. Tomas, Cleto D. Nogueira, Marcos V. A. Lima

Ceará Cancer Hospital (LFGS, JMT, VOP, GAM, MET, CDN, MVAL) and Federal University of Ceará (LFGS, GRML), Ceará. Brazil

\section{ABSTRACT}

Purpose: The study evaluates the clinical and pathological findings of 16 patients with locally advanced penile carcinoma (PC) submitted to emasculation, and discusses questions related to the usefulness of bilateral orchiectomy.

Materials and Methods: Between 1999 and 2010, 172 patients with PC were treated. Sixteen (9\%) underwent emasculation. Data were retrieved from the institution's database including age, ethnicity, date of surgery, residential setting, level of schooling, time to diagnosis, type of reconstruction, complications, tumor stage and grade, vascular and perineural invasion along with invasion of corpus cavernosum, corpus spongiosum, testicles, scrotum and urethra.

Results: A total of 16 patients (average: 63.1 years) with locally advanced PC were included. All were illiterate or semiliterate rural dwellers and 87\% were white. The time to diagnosis was 8-12 months. The mean follow-up time was 31.9 months (1-119). By the time of the last follow-up, only seven patients (43.75\%) were alive. Tumors were pT4 $(n=6)$, pT3 $(n=8)$, pT2 $(n=2)$, Grade I $(n=5)$ and Grade II $(n=11)$. The histopathological examination revealed invasion of the urethra $(n=13)$, scrotum $(n=5)$ and testicles $(n=1)$. The surgical margin was positive in one patient. Six patients $(37.5 \%)$ had vascular invasion and 11 (68.7\%) had perineural invasion. Currently, only one of the former is alive.

Conclusions: The finding of focal microscopic testicular infiltration in only one of 32 testicles, even in the presence of clinically apparent scrotal invasion, suggests that emasculation without bilateral orchiectomy is a safe treatment option for patients with locally advanced PC.

\section{ARTICLE INFO}

\author{
Key words: \\ Orchiectomy; Penile \\ Neoplasms; Carcinoma, \\ Squamous Cell; Penis
}

Int Braz J Urol. 2012; 38: 750-9

Submitted for publication:

February 12, 2012

Accepted after revision:

August 14, 2012

\section{INTRODUCTION}

Penile carcinoma (PC), a potentially fatal malignancy, is rare in developed countries (1). In the United States, for instance, it accounts for only $0.4 \%$ of all male malignancies (2), while in less developed regions, especially in Asia, Africa, and South America, the figure may be as high as $10 \%$ (3). The incidence typically ranges from less than $1 / 100,000$ in the US and Europe to more than 4/100,000 in Uganda and Brazil (4).

Brazil has one of the highest incidences of penile cancer in the world. The disease represents $2.1 \%$ of male neoplasms in the country, reaching $5.7 \%$ in the Northeast (5) where the human development index is very low. Not surprisingly, the region accounts for more than half (53.02\%) of the cases registered in Brazil. In comparison, whe- 
reas 2 or 3 new cases of PC are observed every month at the Ceará Cancer Hospital in Fortaleza (Northeastern Brazil) (6), a British practicing urologist may not see more than one new case every other year.

The causes of penile cancer are not always clear, but major risk factors include poor penis hygiene, phimosis, smegma retention, smoking and sexually transmitted diseases $(7,8)$. In a recent Brazilian multicenter study, the practice of sex with animals was also identified as a risk factor for this malignancy (9).

Penile carcinoma metastasizes stepwise via the lymphatic system: from the inguinal nodes to the pelvic nodes to the distant nodes (10). The presence and extent of lymph node metastases are the most important predictors of survival (4). Histological grade and vascular and perineural invasion have been correlated with poor prognosis and unfavorable outcomes (11).

Surgical management of malignant PC depends on the grade and stage of the disease (12). The National Institute for Clinical Excellence (U.K) recommends managing $\mathrm{PC}$ at centers with a catchment area of 4 million. Each center receives approximately 25 new cases annually. Advanced cases of PC are referred to a supra-regional center for multidisciplinary curative and palliative treatment, including reconstructive surgery (13).

At our service, PC patients with proximal corpus cavernosum invasion and scrotal skin erosion are routinely referred to emasculation, including total penectomy (complete penis amputa- tion), scrotectomy and bilateral orchiectomy (14).

The present study evaluates the clinical and pathological findings of 16 patients with locally advanced penile squamous cell carcinoma submitted to emasculation and discusses questions related to surgical technique, patient follow-up and the usefulness of bilateral orchiectomy.

\section{MATERIALS AND METHODS}

Between 1999 and 2010, 172 patients with penile invasive squamous cell carcinoma were submitted to surgical treatment at the Ceará Cancer Hospital in Fortaleza, Brazil. Of these, 16 advanced cases (9.3\%) underwent emasculation (Table-1).

Complete preoperative, operative and postoperative patient data were retrieved from the institution's prospective database and from a review of the respective medical records. The information included patients' age, ethnicity, date of surgery, residential setting (rural or urban), level of schooling, time from appearance of first lesion to definitive diagnosis, type of reconstruction, duration of follow-up and date of last follow-up visit. The median follow-up time was calculated as the median observation time among patients and the overall survival time was estimated using the Kaplan-Meier method.

Specimens were obtained from all patients and evaluated by a single pathologist with regard to tumor stage and grade, inguinal lymph node status, vascular and perineural invasion, invasion

Table 1 - Cases of penile squamous cell carcinoma submitted to surgical treatment at the Ceará Cancer Hospital between 1999 and 2009.

\begin{tabular}{lcc}
\hline Surgical technique & Cases $(\mathrm{n})$ & Percent (\%) \\
\hline Wide local excision or circumcision & 5 & $3 \%$ \\
Partial penectomy & 125 & $73 \%$ \\
Total penectomy & 26 & $15 \%$ \\
Emasculation & 16 & $9 \%$ \\
\hline Total & 172 & $100 \%$ \\
\hline
\end{tabular}


of corpus cavernosum, corpus spongiosum, testicles, scrotum and urethra.

All 16 patients were submitted to emasculation, including total penectomy, scrotectomy and bilateral orchiectomy. The technique consisted of an elliptical abdominoscrotal incision with large skin margin and partial preservation of the posterior surface of the scrotum. With the corpus cavernosum and corpus spongiosum exposed, the urethra was dissected and mobilized. The corpus cavernosum was disinserted from the ischial tuberosity followed by en bloc removal of the penis, scrotum and testes. The urethra was tunneled without angulation, spatulated and externalized in the perineum, as described by Campbell (15).

The surgical wound was closed with a scrotal flap in 9 patients. Seven patients required two forms of reconstruction: 1) a vertical rectus abdominis myocutaneous flap was made through a midline abdominal incision, preserving the posterior layer of aponeurotic and inferior epigastric vessels. The skin grafts were rotated to achieve complete wound closure; 2) an eliptical incision was made in the medial aspect of the thigh, starting $10 \mathrm{~cm}$ below the ischium, in order to preserve the medial circumflex femoral arteries, followed by wound closure with a gracilis myocutaneous flap. Both reconstruction techniques were performed with the assistance of a plastic surgery team.

Four patients who had previously undergone partial penectomy required emasculation due to tumor recurrence (at 6,2,9 and 13 months, respectively). The previous pathological findings of these patients included: Patient $1=$ pT2 GII, margin $4 \mathrm{~mm}$; Patient $2=$ pT3 GII, positive surgical margin; Patient $3=$ no information available, patient treated at another institution; Patient $4=$ pT2 N2 Mx GI.

Tumors were graded with the most commonly used classification system: grade $\mathrm{I}=$ well differentiated; grade II = moderately differentiated, and grade III = poorly differentiated (16).

At the moment of recurrence, tumors were large with clinical evidence of scrotal erosion and proximal invasion of the corpus cavernosum and the urethra.

Eleven patients underwent lymphadenectomy due to inguinal lymph node involvement.
Pelvic lymphadenectomy was performed in four patients. The pathological nodal status was defined as: $\mathrm{NO}=$ no evidence of lymph node metastasis; N1 $=$ metastasis in a single inguinal lymph node; $\mathrm{N} 2=$ metastasis in multiple or bilateral superficial lymph nodes and $\mathrm{N} 3$ = unilateral or bilateral metastasis in deep or pelvic lymph nodes. The excised tumors were clinically and pathologically staged according to the guidelines of the International Union Against Cancer (2002 TNM UICC) (17).

The study was previously approved by the Institutional Ethics Committee and the principles of the Helsinki Declaration were followed in all study procedures.

\section{RESULTS}

The 16 patients undergoing emasculation were aged 63.1 years on the average (range: 4078). Fourteen patients (87\%) were white and two (13\%) were black. All were illiterate or semiliterate rural dwellers (Table-2). The time from the appearance of the first penile lesion to the definitive diagnosis was 8-12 months.

Radical bilateral inguinal lymphadenectomy was performed in 11 patients 3-4 weeks after emasculation. Due to extensive loco-regional disease, in five patients treatment was limited to surgical debulking for palliative and hygiene purposes, followed by reconstruction (Figure-1).

The pathological nodal status of the $11 \mathrm{pa}-$ tients undergoing radical inguinal lymphadenectomy was N0 $(n=7)$, N2 $(n=3)$ and N3 $(n=1)$. The average number of inguinal lymph nodes was 9.7 (2-19). Among the 4 patients who underwent pelvic lymphadenectomy, the average number of lymph nodes removed was 11.7 (4-20). No patient had positive pelvic lymph nodes. One of the 4 patients with positive inguinal lymph nodes presented a large coalescent mass; the remainder had an average of 2.5 metastatic lymph nodes (2-4).

In most patients $(\mathrm{n}=9)$, the surgical wound was closed with a scrotal flap. The remainder $(n=7)$ required reconstruction with either a vertical rectus abdominis myocutaneous flap ( $\mathrm{n}=$ 4) or a gracilis myocutaneous flap $(\mathrm{n}=3)$.

Tumors were mostly T3 or T4 $(6=\mathrm{pT} 4$, $8=\mathrm{pT} 3,2=\mathrm{pT} 2$ ). Five tumors were well differentia- 
Table 2 - Demographic information, date of surgery, type of reconstruction and last follow-up visit of 16 patients with penile squamous cell carcinoma submitted to emasculation at the Ceará Cancer Hospital in Fortaleza, Brazil, between 1999 and 2010.

\begin{tabular}{|c|c|c|c|c|c|c|}
\hline Patient & Age & Race & $\begin{array}{l}\text { Level of } \\
\text { schooling }\end{array}$ & $\begin{array}{l}\text { Date of } \\
\text { surgery }\end{array}$ & Type of reconstruction & Status on last follow-up visit* \\
\hline I & 64 & White & Illiterate & 2001/05 & Gracilis & Alive DF 2011/04 \\
\hline II & 78 & White & Illiterate & 2004/01 & VRAM & Dead 2005/01 \\
\hline III & 64 & White & Illiterate & $2004 / 06$ & VRAM & Dead 2004/12 \\
\hline IV & 66 & White & Semiliterate & $2004 / 06$ & Gracilis & Alive DF 2011/04 \\
\hline V & 70 & Black & Semiliterate & $2004 / 11$ & Scrotum & Alive DF 2011/04 \\
\hline VI & 52 & White & Illiterate & $2005 / 06$ & VRAM & Dead 2006/10 \\
\hline VII & 53 & White & Semiliterate & $2005 / 01$ & Gracilis & Dead 2005/11 \\
\hline VIII & 67 & White & Illiterate & $2006 / 07$ & Scrotum & Dead 2009/03 \\
\hline IX & 54 & White & Semiliterate & $2006 / 10$ & VRAM & Dead 2007/01 \\
\hline$x$ & 49 & White & Semiliterate & $2007 / 02$ & Scrotum & Alive DF 2011/04 \\
\hline XI & 40 & Black & Illiterate & $2007 / 04$ & Scrotum & Dead 2008/02 \\
\hline XII & 55 & White & Semiliterate & $2007 / 10$ & Scrotum & Alive DF 2011/04 \\
\hline XIII & 77 & White & Semiliterate & $2008 / 01$ & Scrotum & Dead 2008/02 \\
\hline XIV & 73 & White & Semiliterate & $2008 / 11$ & Scrotum & Alive DF 2011/04 \\
\hline XV & 70 & White & Illiterate & $2010 / 02$ & Scrotum & Alive DF 2011/04 \\
\hline $\mathrm{XVI}$ & 78 & White & Illiterate & 2009/11 & Scrotum & Dead 2010/07 \\
\hline
\end{tabular}

*Last follow-up visit: April 2011

DF = disease-free

Figure 1 A-C: Patient with locally advanced penile squamous cell carcinoma submitted to emasculation and reconstruction with a vertical rectus abdominis myocutaneuos flap. Ceará Cancer Hospital, Fortaleza, Brazil.
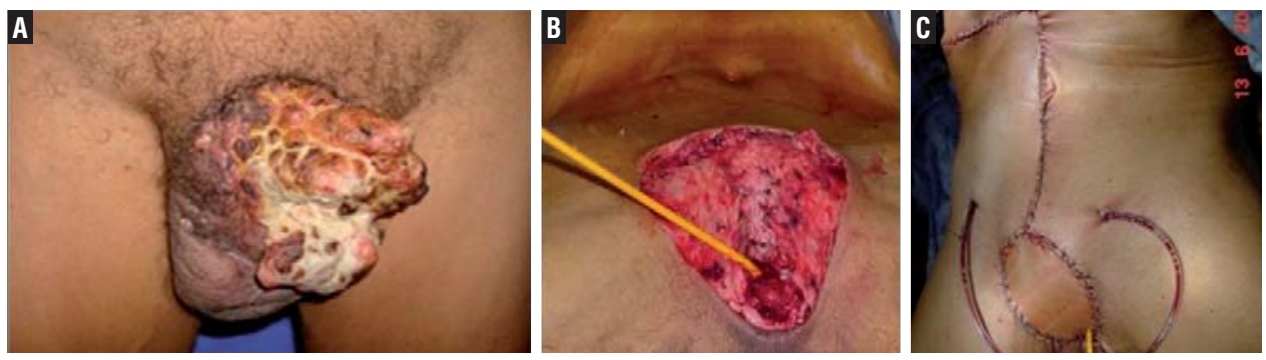
ted (Grade I) and 11 were moderately differentiated (Grade II). No tumor was classified as Grade III and no patient presented distant metastases.

Six (37.5\%) patients had vascular invasion and $11(68.7 \%)$ had perineural invasion. Corpus cavernosum/spongiosum iñvasion was observed in all 16 cases (Table-3). No lymphovascular invasion was observed in patients with Grade-I tumors.
$=5)$ and testicles $(n=1)$. The surgical margin was positive in one patient.

The time of follow-up was 31.9 months on the average (range: 1-119). By the time of the last follow-up visit (April 2011), only 7 patients $(43.75 \%)$ were alive. One of six patients with vascular invasion was alive. A Kaplan-Meier overall survival curve is shown in Figure-2.

Table 3 - Pathological findings of 16 patients with penile squamous cell carcinoma submitted to emasculation at the Ceará Cancer Hospital in Fortaleza, Brazil, between 1999 and 2010.

\begin{tabular}{|c|c|c|c|c|c|c|c|c|c|c|}
\hline Patient & Stage & Grade & Vascular & $\mathrm{Sp} / \mathrm{Cav}$ & Perineural & Testis & Scrotum & Urethra & Margin & pN \\
\hline I & pT4 & II & - & + & + & - & + & + & - & pNO \\
\hline II & pT3 & II & + & + & + & - & - & + & - & $\mathrm{pNx}$ \\
\hline III & pT3 & II & - & + & + & - & - & + & - & pNO \\
\hline IV & pT3 & 1 & - & + & - & - & - & + & - & pNO \\
\hline V & pT3 & I & - & + & - & - & - & + & - & $\mathrm{pNx}$ \\
\hline VI & pT4 & II & + & + & + & - & + & + & + & $\mathrm{pNx}$ \\
\hline VII & pT4 & II & - & + & - & - & + & - & - & $\mathrm{pN} 2$ \\
\hline VIII & pT4 & II & - & + & + & + & - & + & - & pNO \\
\hline IX & pT2 & II & + & + & + & - & - & - & - & $\mathrm{pNx}$ \\
\hline$x$ & pT2 & I & - & + & - & - & - & - & - & pNO \\
\hline$X I$ & pT3 & II & + & + & + & - & - & + & - & $\mathrm{pN} 2$ \\
\hline XII & pT3 & II & + & + & + & - & - & + & - & $\mathrm{pNx}$ \\
\hline XIII & pT3 & II & + & + & + & - & - & + & - & pN3 \\
\hline XIV & pT4 & 1 & - & + & - & - & + & + & - & pNO \\
\hline$X V$ & pT3 & 1 & - & + & + & - & - & + & - & pNO \\
\hline XVI & pT4 & II & - & + & + & - & + & + & - & pN2 \\
\hline
\end{tabular}

$(+)=$ invasion

$(-)=$ without invasion

$\mathrm{Sp} / \mathrm{Cav}=$ Corpus spongiosum and corpus cavernosum

$\mathrm{pN}=$ pathological nodal status

On the other hand, patients with Grade-II tumors presented lymphovascular and perineural invasion $(n=6)$, or perineural invasion only $(n=4)$. A single patient with Grade-II tumor presented no lymphovascular or perineural invasion.

The histopathological examination revealed invasion of the urethra $(n=13)$, scrotum (

\section{DISCUSSION}

The study was motivated by the question of whether bilateral orchiectomy is necessary in patients with locally advanced penile squamous cell carcinoma and scrotal erosion. Emasculation conventionally involves 
Figure 2 - Kaplan-Meier survival curve of 16 patients submitted to emasculation. Data expressed as percentage of live patients over time. Median overall survival was 16 months.

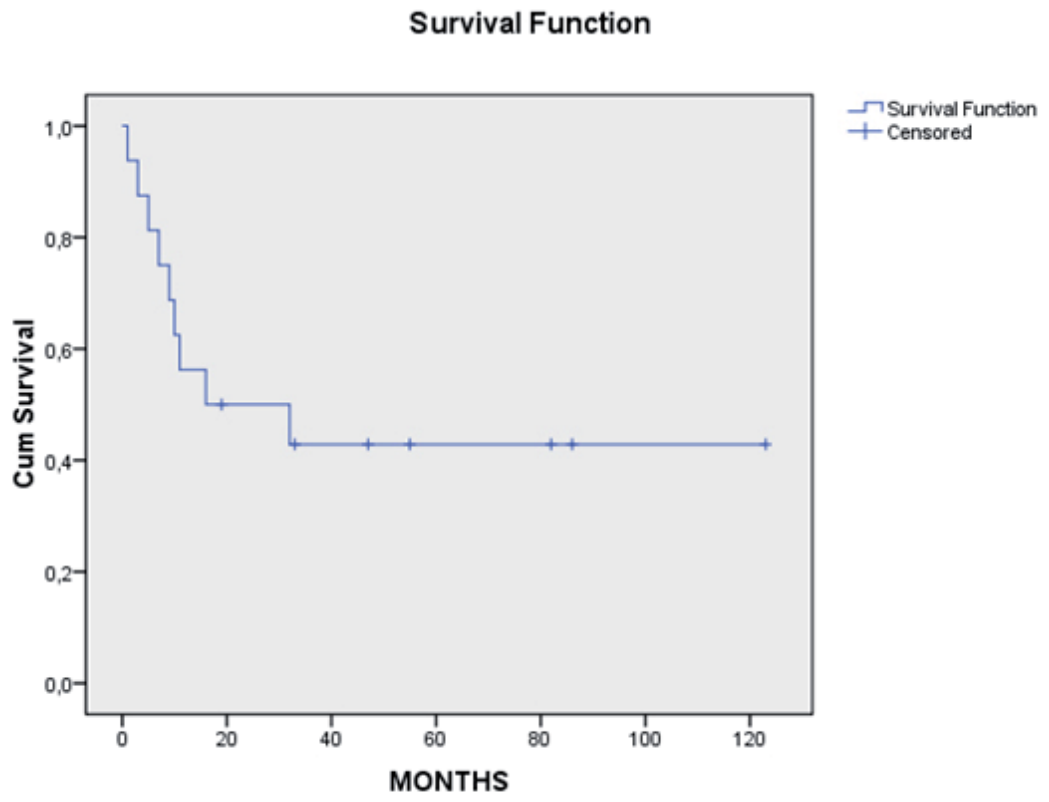

the amputation of penis and testicles and all or part of the scrotum (14).

Although penile amputation can in many subtle and insidious ways give patients an altered sense of masculine identity (18), the crucial question in face of locally advanced PC is not the mutilation per se, but the severity and mortality of the disease.

In our series of PC patients, 9\% (16/172) were submitted to emasculation. In comparison, Ornellas et al. referred only 2\% (15/688) of their PC patients from Rio de Janeiro to emasculation during a period of 46 years (14). However, it seems likely that due to the geographical location of our institution (Northeastern Brazil), a socioeconomically challenged region, $\mathrm{PC}$ is more prevalent and emasculation is more often required.

In addition, diagnosis and follow-up of patients from the rural zone can be very difficult. Some patients wait until after the rainy season or harvest to seek medical care, giving the disease a seasonal character.

Although earlier studies concluded the incidence of PC peaks at 80 years of age (19), more recent investigations have shown the peak to occur in the sixth decade of life (20). In our series, patients were 40-78 years old (mean: 63.1) upon diagnosis.

Favorito et al. reported that $19.41 \%$ of their patients were less than 45 years old, 3.52\% were under 35 and 3.88\% were under 26 (5). In comparison, in our initial sample $(\mathrm{n}=172), 18.7 \%$ were under 45 years old, 7\% were under 35 and 1.7\% were under 26.

PC affects mainly poor, uncircumcised men with poor hygiene and limited access to public health care. The proportion of whites (87\%) among the patients emasculated in this study matched findings published by Favorito et al. (75.61\%) (5). All our patients were illiterate or semiliterate rural dwellers.

The 2002 TNM classification system was adopted throughout the study since all emasculated patients were treated after 2001. Most tumors were pT3 or pT4. Six patients were classified as pT4 due to invasion of the scrotum $(n=5)$ or the testicles $(n=1)$, and two were classified as pT2. One pT2 patient was alive at the time of the last 
follow-up visit 46 months after surgery. The other surviving patients in our series were staged as pT4 $(\mathrm{n}=2)$ and pT3 $(\mathrm{n}=4)$, suggesting that tumor stage is not the only factor determining survival (14). The two patients staged as pT4 were followed for 119 and 29 months, respectively.

Most cases of PC reported in the literature are low-grade (21). Our cases were staged as Grade I (well differentiated; $\mathrm{n}=5$ ) or Grade II (moderately differentiated; $n=11$ ). No tumor was classified as Grade III. Although all Grade-I patients are currently alive, the presence of tumors of both grades (I and II) among the surviving patients suggests a lack of correlation between grade and survival. Johnson reached a similar conclusion in a study of 153 cases (22). On the other hand, Ornellas and Cubillas found histological grade to be a significant adverse prognostic factor for lymph nodes metastasis and survival $(16,23)$.

Clinically, the scrotum appeared to be infiltrated in all 16 cases, but only 5 were confirmed by the pathologist. The single case of microscopic focal testicular infiltration in the absence of scrotal invasion was even more surprising. This infiltration may have been a retrograde extension from the vas deferens--a very rare occurrence (24).

The fact that microscopic focal testicular infiltration was confirmed in only 1 of the 32 testicles in our sample, even in the presence of clinically apparent scrotal invasion, suggests that emasculation without bilateral orchiectomy is a reasonably safe treatment option for patients with locally advanced penile squamous cell carcinoma. As an added benefit, patients not submitted to orchiectomy are spared the serious physiological and psychological adverse effects caused by the procedure, especially those associated with testosterone deprivation, such as metabolic syndrome, anemia, dyslipidemia, arterial hypertension, fatigue, irritability, depression, mood alterations, osteoporosis, bone-related events, muscular atrophy and sleep apnea (25).

One patient had positive surgical margins, proving the choice of surgical technique to be appropriate. The patient survived for 32 months after surgery.

Vascular invasion seems to be a major prognostic factor in patients with PC. Several studies using multivariate analysis have shown a strong correlation between venous and lymphatic embolizations and nodal metastasis (23,26-28).

In a study of 196 patients, Ornelas and coworkers identified 39 (19.9\%) cases of lymphovascular embolization (23). In the present study, 6 cases (37.5\%) of vascular embolization by cancer cells were detected by the pathologist. The difference in the respective incidences may be due to the greater number of advanced cases in our series.

Only one of our 6 patients with vascular invasion is currently alive. The mean postoperative survival time for the group was 16 months. This finding matches results published by Ornelas et al. who reported higher 5-year survival rates in patients without lymphovascular embolization (23).

Cubilla (16) and Ornellas (23) demonstrated that vascular invasion is a more important predictor of metastasis than perineural invasion. In our study, perineural invasion was observed in 11 patients (68.7\%), three (27.3\%) of whom are currently alive. The longest postoperative survival observed in our series (119 months) was a patient with perineural invasion. A recently published paper by Ayalla, Cubilla and Guimaraes et al. correlates higher histological grades, deeper anatomical infiltration and vascular and perineural invasion with higher rates of nodal metastasis and mortalily (29).

Nodal status is an important prognostic factor for PC (4). Thus, in our sample, four of the seven patients staged as No are currently alive, while no patient staged as N2/N3 was alive at the time of the last follow-up.

\section{CONCLUSIONS}

Almost ten percent of our patients with locally advanced penile squamous cell carcinoma were referred to emasculation at the Ceará Cancer Hospital (Fortaleza, Brazil) over a period of 11 years. The fact that microscopic focal testicular infiltration was confirmed in only 1 of the 32 testicles in our sample, even in the presence of clinically apparent scrotal invasion, suggests that emasculation without bilateral orchiectomy may be a reasonably safe treatment option for patients with locally advanced penile squamous cell carcinoma, 
thereby avoiding the severe health problems associated with testosterone deprivation. Further studies are required to support these findings.

\section{CONFLICT OF INTEREST}

None declared.

\section{REFERENCES}

1. Jemal A, Siegel R, Ward E, Hao Y, Xu J, Thun MJ: Cancer statistics, 2009. CA Cancer J Clin. 2009; 59: 225-49.

2. Culkin DJ, Beer TM: Advanced penile carcinoma. J Urol. 2003; 170: 359-65.

3. Pizzocaro G, Algaba F, Horenblas S, Solsona E, Tana S, Van Der Poel $\mathrm{H}$, et al.: EAU penile cancer guidelines 2009. Eur Urol. 2010; 57: 1002-12.

4. Mosconi AM, Roila F, Gatta G, Theodore C: Cancer of the penis. Crit Rev Oncol Hematol. 2005; 53: 165-77.

5. Favorito LA, Nardi AC, Ronalsa M, Zequi SC, Sampaio FJ, Glina S: Epidemiologic study on penile cancer in Brazil. Int Braz J Urol. 2008; 34: 587-91; discussion 591-3.

6. Gonzaga-Silva LF, Tavares JM, Freitas FC, Tomas Filho ME, Oliveira VP, Lima MV: The isolated gamma probe technique for sentinel node penile carcinoma detection is unreliable. Int Braz J Urol. 2007; 33: 58-63; discussion 64-7.

7. Pagliaro LC, Crook J: Multimodality therapy in penile cancer: when and which treatments? World J Urol. 2009; 27: 221-5.

8. Daling JR, Madeleine MM, Johnson LG, Schwartz SM, Shera KA, Wurscher MA, et al.: Penile cancer: importance of circumcision, human papillomavirus and smoking in in situ and invasive disease. Int J Cancer. 2005; 116: 606-16.

9. Zequi Sde C, Guimarães GC, da Fonseca FP, Ferreira U, de Matheus WE, Reis LO, et al.: Sex with animals (SWA): behavioral characteristics and possible association with penile cancer. A multicenter study. J Sex Med. 2012; 9: 1860-7.

10. Hughes B, Leijte J, Shabbir M, Watkin N, Horenblas S: Noninvasive and minimally invasive staging of regional lymph nodes in penile cancer. World J Urol. 2009; 27: 197-203.

11. Cubilla AL: The role of pathologic prognostic factors in squamous cell carcinoma of the penis. World J Urol. 2009; 27: 169-77.

12. Hegarty PK, Shabbir M, Hughes B, Minhas S, Perry M, Watkin $\mathrm{N}$, et al.: Penile preserving surgery and surgical strategies to maximize penile form and function in penile cancer: recommendations from the United Kingdom experience. World J Urol. 2009; 27: 179-87.

13. Hegarty PK, Rees RW, Borley NC, Ralph DJ, Minhas S: Contemporary management of penile cancer. BJU Int. 2008; 102: 928-32.
14. Ornellas AA, Kinchin EW, Nóbrega BL, Wisnescky A, Koifman $\mathrm{N}$, Quirino R: Surgical treatment of invasive squamous cell carcinoma of the penis: Brazilian National Cancer Institute long-term experience. J Surg Oncol. 2008; 97: 487-95.

15. David SS, Kenneth WA: Surgery of penile and urethral carcinoma. In: Walsh PC, Retik AB, Vaughan Jr ED, AJ Wein, Kavoussi LR, Novick AC, et al.: Campbell'S Urology. ed. 9. Philadelphia USA, Saunders. 2007; pp 993-1022.

16. Cubilla AL, Velazquez EF, Ayala GE, Chaux A, Torres J, Reuter $\mathrm{V}$ : Identification of prognostic pathologic parameters in squamous cell carcinoma of the penis: significance and difficulties. Pathol Case Rev. 2005; 10: 3-13.

17. Solsona E, Algaba F, Horenblas S, Pizzocaro G, Windahl T; European Association of Urology: EAU Guidelines on Penile Cancer. Eur Urol. 2004; 46: 1-8.

18. Bullen K, Edwards S, Marke V, Matthews S: Looking past the obvious: experiences of altered masculinity in penile cancer. Psychooncology. 2010; 19: 933-40.

19. Persky L: Epidemiology of cancer of the penis. Recent Results Cancer Res. 1977; 60: 97-109.

20. Horenblas S, Van Tinteren H, Delemarre JF, Moonen LM, Lustig V, Kröger R: Squamous cell carcinoma of the penis: accuracy of tumor, nodes and metastasis classification system, and role of lymphangiography, computerized tomography scan and fine needle aspiration cytology. J Urol. 1991; 146: $1279-83$.

21. Maiche AG, Pyrhönen S, Karkinen M: Histological grading of squamous cell carcinoma of the penis: a new scoring system. Br J Urol. 1991; 67: 522-6.

22. Johnson DE, Fuerst DE, Ayala AG: Carcinoma of the penis. Experience with 153 cases. Urology. 1973; 1: 404-8.

23. Ornellas AA, Nóbrega BL, Wei Kin Chin E, Wisnescky A, da Silva PC, de Santos Schwindt AB: Prognostic factors in invasive squamous cell carcinoma of the penis: analysis of 196 patients treated at the Brazilian National Cancer Institute. J Urol. 2008; 180: 1354-9.

24. Gow KW, Murphy JJ 3rd, Wu JK, Desa DJ: Metastatic testicular rhabdomyosarcoma--a report of two cases. J Pediatr Surg. 2003; 38: E1-3.

25. Traish AM, Saad F, Feeley RJ, Guay A: The dark side of testosterone deficiency: III. Cardiovascular disease. J Androl. 2009; 30: 477-94.

26. Bhagat SK, Gopalakrishnan G, Kekre NS, Chacko NK, Kumar $S$, Manipadam MT, et al.: Factors predicting inguinal node metastasis in squamous cell cancer of penis. World J Urol. 2010; 28: 93-8.

27. Slaton JW, Morgenstern N, Levy DA, Santos MW Jr, Tamboli P, Ro JY, et al.: Tumor stage, vascular invasion and the percentage of poorly differentiated cancer: independent prognosticators for inguinal lymph node metastasis in penile squamous cancer. J Urol. 2001; 165: 1138-42. 
28. Ficarra V, Zattoni F, Cunico SC, Galetti TP, Luciani L, Fandella A, et al.: Lymphatic and vascular embolizations are independent predictive variables of inguinal lymph node involvement in patients with squamous cell carcinoma of the penis: Gruppo Uro-Oncologico del Nord Est (Northeast Uro-Oncological Group) Penile Cancer data base data. Cancer. 2005; 103: 2507-16.
29. Guimarães GC, Cunha IW, Soares FA, Lopes A, Torres J, Chaux $A$, et al.: Penile squamous cell carcinoma clinicopathological features, nodal metastasis and outcome in 333 cases. J Urol. 2009; 182: 528-34; discussion 534.

Correspondence address: Dr. Lúcio Flávio Gonzaga-Silva Av. Pe. Antonio Tomás, 2200/1100, Aldeota Fortaleza, CE, 60140-160, Brazil Telephone: +55 85 3267-2574

E-mail: gonzaga-silva@ufc.br; gonzaga-silva@portalmedico.org.br 


\section{EDITORIAL COMMENT}

This is an interesting study, showing several clinical epidemiological and demographic aspects of patients with agressive locally advanced penile cancer, some of them under 50 years old, treated by a skilled team from a tertiary cancer center located in a highly prevalent penile cancinoma area.

Despite its reduced casuistry (16 cases), it brings us a very important new information, that probably has been noted in the daily practice, but was not present in the scientific literature: In the vast majority of debulking surgeries for locally advanced penile cancer, the testis are spared by the disease, probably due the anatomical barriers, as dartos muscles, albuginea and vaginal layers, then they do not deserve to be removed.

Many of this patients will die early due the disease progression. However more than a third of them can be cured or will develop later recurrences (in this present series 7 are alive for long time).

Testosterone plays several important roles in male physiology. If the castration is avoided in this clinical scenario, the long term survivors, will not develop several serious health conditions due androgen deficiency like: metabolic syndrome, anemia, dyslipidemia, arterial hypertension, fatigue, irritability, depression, mood alterations, osteoporosis, bone-related events, muscular atrophy, sleep apnea and others. And for the anedoctal minority of cured subjects seeking for penile reconstruction, the libido persistence will be warranted.

As shown, vascular invasion was a unfavorable anatomopatological pattern, probably this patients deserve an adjuvant chemotherapy or can be candidates for future clinical trials.

Dr. Stênio de Cássio Zequi Urologia / Oncologia, Fundação Antônio Prudente - São Paulo Rua Batataes, 391 - 4o. andar, Jardim Paulista São Paulo, SP, 01423-010, Brazil E-mail: steniozequi@uol.com.br 